an increase in rate of rise and, in some cases, a prolongation of its decay time, as a consequence of the addition of adrenaline. As the 'generator potentials' would normally present spontaneous fluctuations in shape in the course of the experiments, statistical analysis of the changes caused by the amines was necessary. The modifications in 'generator potential' mentioned above proved to be highly significant. The possibility of an antagonistic effect between adrenaline and procaine being responsible for these modifications may be discarded, since the same changes in 'generator potential' were found when other entirely different procedures for blocking of the action potential were used. A similarity between the facilitatory effects of adrenaline at diverse structures at which impulses are generated becomes apparent by comparing the increment of the 'end plate potential' of skeletal muscle ${ }^{4}$, the alteration in the 'generator potential' of the heart's pacemaker ${ }^{5.6}$ and the changes in 'generator potential' of a sensory nerve ending reported here.

This work was aided by a grant from the Rocke. feller Foundation.

W. R. LOEWENSTEIN

R. Altamirano-Orrego

Instituto de Fisiología,

Universidad de Chile, Casilla 6524,

Santiago, Chile. Aug. 20.

${ }^{1}$ Loewenstein, W. R., J. Physiol., 132, 40 (1956).

${ }^{2}$ Gray, J. A. B., and Malcolm, J. L., Proc. Roy. Soc., B, 137, 96 (1951). ${ }^{3}$ Gray, J. A. B., and Sato, M., J. Physiol., 129, 594 (1955).

- Hutter, O. F., and Loewenstein, W. R., J. Physiol., 130, 559 (1955),

s del Castillo, J., and Katz, B., Nature, 175, 1035 (1955).

- Hutter, O. F., and Trautwein, W., Nature, 178, 512 (1955).

\section{Binding of Histamine in Mammalian Tissues}

MUCH of the histamine in mammalian tissues is contained in tissue mast cells ${ }^{1}$; but it is by no means certain how it is held at high concentration inside these cells. Fvidence suggests that the mast cells do not produce the histamine but have a specitic faculty of storing this compound. However, storage does not occur until metachromatically staining granules of heparin become visible in the cytoplasm of the cells. Experiments have been carried out, therefore, to study the affinity of histamine and heparin for one another.

When heparin $(20 \mathrm{mgm}$.) and histamine acid phosphate (l mgm.) are mixed in solution, and alcohol (70 per cent) or acetone is added, the precipitated heparin removes about 70 per cent of the histamine from the solution when the $p \mathrm{H}$ is around 5 . The combination, however, is dependent upon $p \mathrm{H}$, since at neutral or alkaline reaction much less histamine is removed by the heparin. Fig. 1 illustrates this point and compares the combination of heparin and histamine base $(B, p H 9)$ with that of heparin and histamine acid phosphate or dihydrochloride. The precipitated heparin-histamine complex can be washed with alcohol or acetone without loss of histamine, but the complex is easily rendered soluble by water, saline or weak acid. If adenosine triphosphate $(1 \mathrm{mgm}$.$) is also present in the solution$ before precipitation, the uptake of histamine by heparin is increased to more than 90 per cent.

The staining properties (for example, with toluidine blue) and chromatographic behaviour of the complex resemble those of the natural mast ceil granules

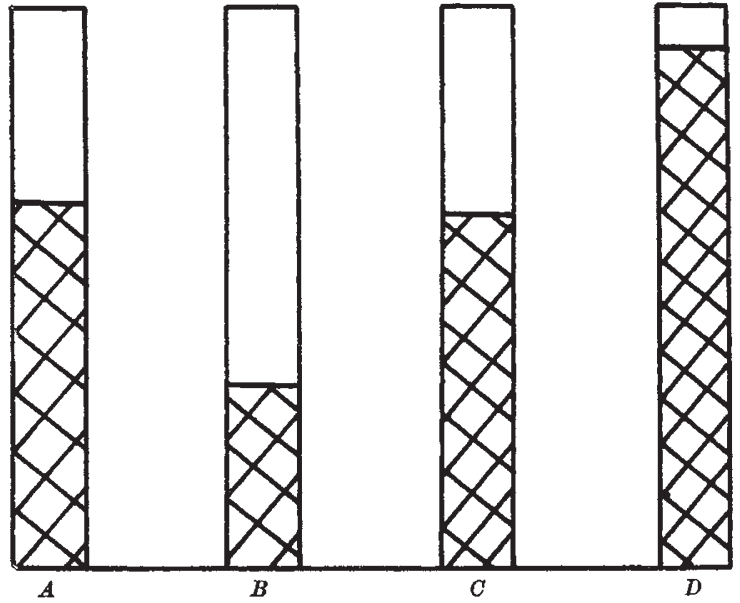

Fig. 1. Diagram to illustrate the distribution of histamine between the supernatant liquid (clear areas) and the precipitate of heparin (shaded areas). $A$, Histamine acid phosphate; $B$, histamine base; $C$, histamine dihydrochloride; $D$, histamine acid phosphate with adenosine triphosphate. All columns represent the means of ten experiments

isolated from mouse connective tissue ${ }^{2}$. Further, the morphological characters of the precipitated complex approximate to those of the living granules.

The formation of the complex is fairly specific for histamine, since adrenaline, noradrenaline and 5hydroxytryptamine are not removed under similar conditions. Certain basic amino-acids such as arginine, lysine or ornithine combine with heparin when alcohol is added ${ }^{3}$; and it is of interest to find that these amino-acids are bases of sufficient strength to displace histamine from its attachment to the acidic residue of heparin in the tissues by some kind of cation exchange ${ }^{4}$.

Thus the base histamine and the acid heparin can form a complex in vitro. The proportions of the two substances present in the complex, namely, one part of histamine to twenty parts of heparin, are similar to those found in extracts of tissues which are rich in mast cells ${ }^{5}$. So far it has not been possible to release the histamine from the synthetic histamine heparinate without solution of the heparin.

R. K. SANYAL

G. B. West

Department of Pharmacology,

School of Pharmacy,

Bloomsbury Square,

London, W.C.1.

Sept. 25.

${ }^{1}$ Riley and West, J. Physiol., 120, 528 (1953).

${ }^{2}$ West, J. Pharm. Pharmacol., $\mathrm{z}, 80$ (1955).

${ }^{3}$ Amman and Werle, Klin. Wechr., 34, 207 (1956).

4 Eldridge and Paton, $J$, Physiol., 124, 27 P (1954).

${ }^{\circ}$ Cass, Riley, West, Head and Stroud, Nature, 174, 318 (1954).

\section{Enzyme-Substrate Complex Formation : a First Stage in Ribonuclease Activity}

THE exact intermediate steps in the breakdown caused by ribonuclease enzymic activity awaits clarification in spite of the many methods currently used in the measurement of ribonuclease activity.

The method presented here was found very useful for demonstrating the stepwise ribonuclease enzymic specificity. The technique depends on the fact that basic dyes which normally polymerize in aqueous 